\title{
Planejamento Estratégico como exigência ética para a equipe e a gestão local da Atenção Básica em Saúde
}

José Roque Junges(a)

Rosangela Barbiani ${ }^{(b)}$

Elma Lourdes Campos Pavone Zoboli ${ }^{(c)}$

Junges JR, Barbiani R, Zoboli ELCP. Strategic planning as an ethical requirement for primary healthcare teams and local management. Interface (Botucatu). 2015; 19(53):265-74.

The premises that individuals cannot be cared for without meeting group needs and that attendance and management cannot be separated show that moral deliberations on clinical action regarding individual care cannot be dissociated from strategic planning by local teams and management. This planning needs to be integrated with surveillance, to detect health-related needs within the attendance context. It should be linked to municipal central management so as to make agreements regarding the intersectoral actions necessary for expanding individuals' and populations' healthcare. For moral decisions involving clinic deliberation to be made, certain conditions that depend on strategic planning in this field are required. It can be seen that the processes of moral deliberation proposed by Gracia and strategic planning proposed by Matus present cognitive, valuationrelated, operative and evaluative stages that are largely homologous. This paper ends with a complex concrete case of primary care in which these different stages were implicated.

Keywords: Primary healthcare. Ethics. Management. Surveillance. Strategic planning.
As premissas de que não se pode cuidar de indivíduos sem atender seus coletivos e atenção e gestão são indissociáveis, mostram que a deliberação moral da clínica no cuidado individual não pode dissociar-se do planejamento estratégico da equipe e gestão local. Esse planejamento precisa estar integrado com vigilância para detectar necessidades em saúde do contexto de atendimento, articulado com a gestão central do município para pactuar ações intersetoriais necessárias para o cuidado da saúde ampliada dos indivíduos e da população. Decisões morais de deliberação clínica exigem, para sua concretização, de condições e meios, dependentes do planejamento estratégico no território. Consultando o processo de deliberação moral proposto por Gracia e de planejamento estratégico por Matus, descobre-se grande homologia entre suas etapas: cognitivo; valorativo; operativo; avaliativo. Conclui-se com a apresentação de um caso concreto complexo de atenção básica onde estão implicadas essas etapas.

Palavras-chave: Atenção Básica à Saúde. Ética. Gestão. Vigilância. Planejamento Estratégico

\footnotetext{
(a) Programa de PósGraduação em Saúde Coletiva, Universidade do Vale do Rio dos

Sinos (Unisinos). Avenida Unisinos, 950. São Leopoldo RS, Brasil. 93022630.roquejunges@ hotmail.com

(b) Programa de Pós-Graduação em Enfermagem, Unisinos. Porto Alegre, RS, Brasil. barbiani@unisinos.br

(c) Departamento de Enfermagem em Saúde Coletiva, Escola de Enfermagem, Universidade de São Paulo. São Paulo, SP, Brasil.elma@usp.br
} 


\section{Introdução}

As políticas públicas incentivam e a prática do atendimento demonstra a necessária integração entre clínica e vigilância nos serviços de Atenção Básica à Saúde (ABS), porque o foco é a resolutividade das necessidades em saúde de uma população adscrita. Essas necessidades precisam ser detectadas pela vigilância no âmbito sanitário daquele território e respondidas, individual e coletivamente, pela clínica e por ações intersetoriais sanitaristas.

Essa constatação aponta para um primeiro pressuposto da atenção básica: não se consegue atender as pessoas individualmente em suas necessidades de saúde se elas não são cuidadas e acompanhadas no coletivo por meio de ações de prevenção e promoção para aquele território; e, por outro lado, não se protege e promove o coletivo em sua saúde se os indivíduos desse coletivo não são cuidados em suas necessidades individuais ${ }^{1}$. Esse primeiro pressuposto ancora-se num segundo, que é uma exigência do anterior: a indissociabilidade entre atenção e gestão ${ }^{2}$, porque, para se integrar o foco no indivíduo e no coletivo da atenção, é indispensável aproximá-la da gestão, já que é necessário integrar atividades de atendimento e de planejamento nos serviços.

Contudo, essa integração entre clínica e vigilância na atenção básica e a consequente necessidade da aproximação entre atenção e gestão têm demonstrado dificuldades de execução, pois cada uma delas responde a lógicas diversas. A clínica está focada nas necessidades subjetivas do indivíduo e a vigilância nos riscos à saúde de um coletivo; a primeira obedecendo mais a uma racionalidade clínica de interpretação ampliada de uma queixa subjetiva, e, a segunda, a uma racionalidade epidemiológica e sanitarista de riscos que tem bases objetivas e científicas e, em muitos casos, consequências jurídicas. Por outro lado, a atenção caracteriza-se pela lógica do atendimento individual e coletivo aos usuários, enquanto a gestão está preocupada com uma lógica organizacional de racionalização e distribuição equitativa dos diversos recursos necessários à saúde.

A aproximação e integração dessas racionalidades e lógicas diversas interagindo na atenção básica são um desafio, porque se trata de interfaces que necessitam ser construídas por usuários, profissionais e gestores, já que elas não estão dadas. Por isso, elas se tornam desafios éticos que se traduzem em exigências morais. Daí a necessidade de se refletir sobre o papel da bioética nessas interfaces das redes de atenção à saúde.

A bioética apresenta-se como um processo de deliberação individual e coletiva, a fim de buscar a melhoria da vida humana individual e, sobretudo, coletiva. Na bioética, já está bem desenvolvida a aplicação do método de deliberação moral para a clínica hospitalar ${ }^{3,4}$, que pode ser considerada como mais voltada as melhorias individuais. Entretanto, a clínica adequada e ampliada para a atenção básica depende da vigilância, para definir as necessidades em saúde coletivas daquele território, e da gestão, para transitar nas redes de atenção à saúde. Em outras palavras, não basta deliberar moralmente, é necessário planejar estrategicamente, porque a deliberação da resposta depende de condições coletivas, organizacionais e intersetoriais construídas pelo planejamento. Por isso, uma bioética da atenção básica não pode reduzir-se às exigências morais do deliberar clínico, mas precisa incluir o planejar estratégico como exigência moral advinda das suas interfaces com a vigilância e com a gestão.

Pode parecer que a questão ética se reduz à deliberação, porque se trata de um sujeito singular que, finalmente, toma a decisão e executa o melhor curso de solução; enquanto o planejar implica uma equipe, um sujeito coletivo, que participa da formulação do plano, das suas estratégias de ação e da sua consecução. As normas de assistência à saúde nos sistemas, como o brasileiro, implicam validez universal, então, estas devem se decidir com a efetiva participação de todos que podem ser afetados por elas, em espaços onde: os expertos são assessores; os políticos, gestores; os usuários, pessoas titulares de direitos humanos ${ }^{5}$.

Tendo presente que a atenção básica não existe sem processos de trabalho em equipe e, portanto, sem um sujeito coletivo de corresponsabilidade, tanto na deliberação quanto no planejamento, pode-se entender que os problemas morais da atenção básica necessitam de uma reflexão ética na perspectiva do sujeito coletivo.

O que é esse sujeito coletivo? Trata-se de um coletivo de subjetividades que detém um "idioma" comum, no sentido chomskiano, isto é, a competência social que permite a troca comunicativa entre 
indivíduos distintos de uma mesma cultura, e a representação e expressão criativa do pensamento desse contexto de relações ${ }^{6}$. Esses indivíduos se organizam reflexivamente em vista do alcance de um objetivo comum, e se subjetivam a partir das interações desse coletivo ${ }^{7}$. A equipe de atenção básica é um exemplo típico de um sujeito organizativo profissional, pois seus membros possuem: competência social comunicativa, organização estratégica para a consecução de um fim, e subjetivação a partir do seu coletivo. Esses elementos são a base para a consciência sanitária, isto é, o reconhecimento e o pertencimento à identidade e à corresponsabilidade nos processos de produção da saúde.

Se esses atributos são centrais para a equipe da atenção básica, enquanto sujeito coletivo profissional, sua ética correspondente terá como referência moral os resultados e as consequências das suas ações implementadas, e não a boa intenção, pois se trata de uma ética da responsabilidade ${ }^{8,9}$. Essa dimensão ética aproxima-se do conceito de "ecologia da ação" de Morin ${ }^{10}$, isto é, qualquer ação escapa à vontade dos seus autores, porque sofre as retroações do ambiente no qual ela se insere, podendo ser desviada e distorcida do seu sentido original. Por isso, os efeitos de uma ação dependem não apenas da intenção do autor, porém, mais das condições do meio no qual ela acontece. Daí a necessidade de uma estratégia para concretizar os efeitos visados ${ }^{10}$. Por isso, não basta pura deliberação moral, é necessário complementá-la com planejamento estratégico do ambiente coletivo no qual acontecem e incidem as ações.

Considerando esse cenário, o artigo tem o objetivo de discutir, no âmbito da bioética, a necessidade de a atenção básica complementar a deliberação moral da clínica com a exigência ética do planejamento estratégico da gestão local, articulado com as ações da vigilância em saúde e a macrogestão do sistema de saúde.

\section{Deliberação moral na clínica}

Diego Gracia ${ }^{3,4}$ desenvolveu uma metodologia adequada e pertinente para a deliberação moral no âmbito da clínica. Parte da constatação de que toda deliberação clínica, exercício essencial para o médico chegar ao juízo clínico, é, ao mesmo tempo e sempre, uma deliberação moral, porque permanentemente estão implicados deveres, bens e valores da profissão, do profissional e do paciente que está sendo atendido. Nesse sentido, pode-se afirmar que toda deliberação clínica é sempre, também, uma deliberação moral. Para formular essa metodologia de deliberação moral na clínica, Gracia inspira-se na tradição aristotélica da fronesis, traduzida, para o latim, como prudentia, mas que seria melhor traduzir, nas línguas modernas, por discernimento ou deliberação.

Gracia ${ }^{3,4}$ propõe três momentos do procedimento deliberativo: momento cognitivo, que aponta e sopesa os fatos que configuram o caso clínico; momento valorativo, que discerne e estima os bens e valores implicados no caso; e o momento da realização, que é o momento propriamente moral, que consulta e pondera os deveres que dizem respeito ao caso. Assim, o procedimento deliberativo, segundo Gracia, engloba uma deliberação sobre fatos a serem esclarecidos, sobre valores a serem identificados, sobre deveres para se encontrar o melhor curso de ação para esse caso concreto, e, por fim, sobre as responsabilidades, submetendo esse melhor curso de ação para o problema, às provas de consistência, viabilidade e legalidade ${ }^{11}$.

Para Gracia ${ }^{3,4}$, a maior dificuldade para esse procedimento deliberativo encontra-se no terceiro momento, quando é necessário ponderar e deliberar o melhor curso de ação para o problema moral que se apresenta no caso clínico em análise. Na operacionalização do processo, a tendência é dar-lhe uma solução dilemática, fixando-se apenas em dois cursos extremos de ação, que convergem para os dois valores em conflito. Por exemplo, partindo do conflito de valores morais no caso clínico da necessidade de transfusão de sangue num paciente que seja testemunha de Jeová, o dilema estaria entre respeitar a autonomia do paciente, não dando sangue, ou aplicá-lo para salvar a vida do paciente por beneficência ${ }^{11}$.

Para Gracia ${ }^{3,4}$, essa fixação nos cursos extremos de ação impede de ver e ponderar os cursos intermediários, transformando o que é um problema moral em um dilema moral. A deliberação é justamente uma metodologia que ajuda a não transformar, em dilema conflitivo, o que é um problema moral, exigindo a ponderação dos vários cursos de ação ${ }^{11}$. 
$\mathrm{Na}$ atenção básica, esses diversos cursos de ação para resolver um problema dependem, para sua efetividade, de condições coletivas sanitaristas e intersetoriais, e da conectividade e acesso aos diversos pontos da rede de atenção à saúde. Por isso, não basta apenas deliberar para o caso particular, é necessário planejar estrategicamente para criar e dar as condições ambientais e estruturais para que esses cursos de ação possam ser assumidos e trilhados efetivamente por usuários e profissionais na busca da solução de uma necessidade em saúde.

$\mathrm{Na}$ atenção básica, tanto o deliberar quanto o planejar dependem da cultura organizacional vigente, nos níveis macro e micro de gestão do sistema. A gestão local e central dos processos de trabalho e da organização dos serviços determina, em grande escala, a dinâmica de relacionamento da rede. A gestão participativa - com reuniões semanais, para discutir, planejar e pactuar o atendimento à população, a implementação da metodologia do apoio matricial, a criação de conselhos locais, a participação das equipes na gestão municipal e no controle social - é um curso de ação construtor da indissociabilidade entre atenção e gestão e da interação estratégica de corresponsabilidade necessária às deliberações morais resolutivas.

\section{Planejamento estratégico na gestão}

Para uma ética da responsabilidade, agir moralmente pela deliberação significa sempre e, ao mesmo tempo, agir estrategicamente pelo planejamento, porque a referência moral se traduz nos resultados da ação visada. Nesse sentido, o planejamento estratégico torna-se uma exigência e um imperativo ético do sujeito coletivo da equipe de atenção básica, considerando a indissociabilidade entre atenção e gestão.

Para introduzir o planejamento no âmbito da ética, é necessário definir como se entende a metodologia do planejar. O planejamento pode ser uma pura tecnologia ou ferramenta aplicada e direcionada para a construção de um plano de ação por quem tem expertise técnica, sem a participação de um sujeito coletivo, identificado com a realidade que se quer transformar. A lógica operante nesse modelo é a da razão instrumental. Ou o planejamento pode ser um dispositivo, onde o mais importante não é o produto, isto é, o plano ou projeto de ação, mas o processo, isto é, o caminho de sua produção, possibilitando uma nova subjetivação dos participantes, com suas potencialidades de estabelecer contratos e compromissos na seleção de prioridades em vista da consecução do fim visado. Nesse segundo sentido, o planejamento segue a lógica da razão crítica e propositiva, constituída pela prática contínua da equipe numa perspectiva teleológica de fins a construir, exigindo pensar a permanente interação entre gestão e processos de trabalho ${ }^{7}$. Só esse modelo de planejamento, pela sua dimensão de reflexividade e subjetivação, pode fazer parte de uma ética da responsabilidade.

A discussão sobre o planejamento na área da saúde pública já tem um longo percurso de experiências e análises no Brasil ${ }^{12-16}$. A tendência que mais se adéqua à compreensão do planejamento como dispositivo para potencializar a participação é a do agir comunicativo, pois a racionalidade do processo gerencial vai além dos fins a alcançar, incluindo "o mundo da vida dos atores envolvidos numa postura dialógica que motive a construção de projetos que possam ser assumidos coletivamente como compromissos"17 (p. 357).

Para esse processo, é importante levar em consideração as estruturas mentais da cultura organizacional dos ambientes de trabalho que influenciam as práticas rotineiras, e a possibilidade da construção de novas representações por meio da participação no processo comunicativo e da gestão por compromisso. Para isso, é essencial valorizar a reflexão para não cair numa padronização mecânica das práticas e distribuição fragmentada do poder, apontando para um modelo de gestão negociada. Nesse modelo, é indispensável estratégia de negociação cooperativa e competência para a liderança interativa ${ }^{17}$.

Uma das principais referências dessa tendência para a explicitação da proposta metodológica é a obra clássica de Matus ${ }^{18}$ sobre planejamento estratégico situacional. Para esse autor, o planejamento depende de uma gestão descentralizada, a definição de objetivos a partir de problemas e a análise da viabilidade e da estratégia de sua solução. Ele prevê quatro momentos em seu planejamento estratégico situacional: explicativo, normativo, estratégico e tático-operacional. O primeiro momento 
é a seleção e análise dos problemas relevantes que pedem solução na visão dos atores envolvidos. O segundo momento é a definição da situação-objetivo futura que se quer atingir e quais são as operações necessárias para se obterem resultados, tendo presente os nós críticos dos cenários possíveis. O terceiro momento é a análise da viabilidade desse plano de operações em suas diferentes dimensões: política, econômica, cognitiva e organizativa. O quarto momento é a gestão e o monitoramento operacional da execução do plano ${ }^{16}$.

\section{A deliberação clínica e o planejamento estratégico como exigências éticas complementares da atenção básica}

A equipe de atenção básica, como porta de entrada do sistema de saúde, está preparada para desenvolver a prática clínica na resposta às necessidades em saúde da população, mas uma clínica ampliada de cunho generalista, que não se identifica com a clínica hospitalar e especializada e, portanto, não utiliza tecnologias duras mais sofisticadas para o diagnóstico e a proposta terapêutica. Por isso, pode parecer que ela não enfrenta conflitos e problemas morais por não usar e aplicar instrumentos tecnológicos e não lidar com situações-limite de início e fim de vida. Ao contrário, a atenção básica, em sua prática clínica, também enfrenta conflitos e problemas morais não caracterizados pela densidade tecnológica, mas pelas complexas interações longitudinais dos processos de saúde-doença, pelos determinantes sociais da saúde e suas expressões no território. Existe menos sensibilidade e consciência para a necessidade de deliberação moral sobre esses últimos problemas do que para os primeiros. O desafio neste contexto de cuidados primários é realizar uma deliberação moral em equipe, enquanto sujeito coletivo do processo de decisão e da corresponsabilidade clínica e sanitária.

Quanto aos problemas a enfrentar, é importante ter presente que a atenção básica lida tanto com problemas-fim, que se referem ao estado de saúde dos indivíduos e da população adscrita, quanto com problemas-meio que dizem respeito ao funcionamento e acesso à rede de serviços de saúde e a outras instâncias intersetoriais, necessários para o equacionamento resolutivo das necessidades de saúde da população ${ }^{14,16}$.

Para responder aos problemas-fim, é necessário conhecer as condições de saúde da população por meio da coleta de dados e da produção de informações, investigadas e desenvolvidas pela vigilância em colaboração com a atenção básica. Os problemas-meio precisam ser equacionados pela equipe local nas instâncias de gestão governamental e de controle social, com vistas à construção e pactuação das condições para o cuidado da população.

Tanto as respostas aos problemas-fim, referentes às condições de saúde, como as soluções aos problemas-meio, concernentes aos serviços necessários à saúde da população, necessitam de planejamento, porque o seu equacionamento significa criar as condições organizacionais e materiais para um diagnóstico individual e coletivo adequado (vigilância) e para uma proposta de cuidado clínico e sanitarista integral (gestão). Portanto, o planejamento é a base para uma integração da atenção básica com a vigilância e para uma indissociabilidade dessa atenção com a gestão.

Considerando as contribuições teórico-metodológicas de Gracia e de Matus, e seus respectivos objetos de estudo (deliberação moral e planejamento estratégico), propõe-se um quadro de referência para a integração dessas dimensões da deliberação e do planejamento nas ações da Atenção Básica e da Vigilância em Saúde, por meio da mediação de quatro momentos/etapas, conforme apresentado no Quadro 1.

Em permanente movimento dialético, esses dispositivos constituem processos de construção e de desconstrução de fluxos de ação, cada um deles interferindo com sua especificidade: o cognitivo opera com o levantamento dos fatos e dos problemas implicados no caso que se quer resolver; o valorativo ausculta os valores que estão em conflito, que incidem nas respostas ao caso, e os bens/fins que se querem atingir na resposta; o operativo aponta as operações necessárias para encaminhar a solução do caso, ou seja, os cursos de ação; e o avaliativo acompanha e monitora a execução do plano de operações deliberado ou planejado, para dar conta da responsabilidade ética. Esses processos hão de se guiar por um tipo de racionalidade que permita a participação de todos os implicados no processo 
de deliberação dos problemas práticos, pois passamos da imposição à autogestão, o que requer hábitos deliberativos e de planejamento ${ }^{19}$. Com isso, se introduz o planejamento na ética e se fomenta a bioética como ética da responsabilidade.

Quadro 1. Homologia entre as etapas da deliberação e do planejamento

\begin{tabular}{|l|l|l|}
\hline Momentos/etapas & \multicolumn{1}{|c|}{ Deliberação moral (clínica) } & Planejamento Estratégico (vigilância e gestão) \\
\hline Cognitivo: fatos & Fatos relevantes para entender o caso clínico & Problemas relevantes que pedem solução \\
\hline Valorativo: valores & Valores implicados na decisão sobre o caso & Situação-objetivo, que é o fim que se quer atingir \\
\hline Operativo: operações & Deveres que incidem na solução do caso & $\begin{array}{l}\text { Plano de operações, que aponta para a sua } \\
\text { viabilidade }\end{array}$ \\
\hline Avaliativo: responsabilidades & Responsabilidades assumidas na execução & Gestão e monitoramento da execução do plano \\
\hline
\end{tabular}

Para entender essa interação e implicação mútua entre deliberação e planejamento, nas ações de Atenção Básica e Vigilância à Saúde, toma-se como exemplo um caso concreto de atendimento de uma equipe que atua na atenção primária do SUS. Os nomes das pessoas são fictícios. Essa equipe atende Judite e sua família. Antes de mais nada, é necessário conhecer os fatos implicados no caso. É o momento cognitivo.

Judite tem trinta anos, é solteira e sem filhos, e, há dez anos, convive com o diagnóstico de esquizofrenia. Sua mãe, Dona Vera, sofre de problemas de coluna e tem deficiência auditiva, e seu pai sofre de artrite e caminha com dificuldade. Judite tem uma irmã mais jovem, Marta, que não apresenta nenhuma patologia, levando uma vida independente, não se envolvendo com os problemas familiares. Ela formou-se em pedagogia e está procurando trabalho. Junto com a família vive uma tia-avó que sofre de diabete e teve a perna amputada. A família tem sua condição de saúde agravada pela situação de extrema vulnerabilidade social. Ocupa um apartamento cedido pelo Departamento Municipal de Habitação (DEMHAB), do qual receberam uma ordem de despejo por irregularidades, decisão que foi sustada pela justiça, devido à situação da tia-avó em cadeira de rodas e com muita idade, porque não tinham para onde ir. Após dois meses da retomada do apartamento, a tia-avó faleceu e a família estava, novamente, com o direito à moradia ameaçado.

No processo de acompanhamento da usuária, outra situação-limite fora desvelada, colocando a equipe diante de diversos problemas morais. A equipe, que apostava no pai como membro cuidador, foi descobrindo, aos poucos, que ele boicotava o tratamento psiquiátrico da filha, porque abusava sexualmente dela.

Nesse período e, na sequência de episódios de perda e sofrimento extremo, o pai de Judite veio a óbito. Tendo falecido a tia-avó e o pai, a família nuclear ficou reduzida a três pessoas: a mãe, Sra. Vera, com dificuldades de locomoção e com deficiência auditiva; Judite, com sofrimento mental crônico, e a sua irmã, Marta, professora.

Nessa nova configuração familiar, agravada pela privação socioeconômica, a equipe da saúde da família começou a aproximar-se dessa filha mais jovem para tentar encontrar um apoio como cuidadora.

O que significa deliberar clinicamente e planejar estrategicamente neste caso?

Tendo explicitado os fatos, começa o momento valorativo que aponta para o fim que se quer atingir. Pela complexidade da situação apresentada, fica evidente que uma clínica baseada na avaliação queixa-conduta-prescrição está fadada ao fracasso. Mesmo a deliberação moral não pode reduzir-se ao dilema entre defender a dignidade de Judite e acusar o pai devido aos abusos, nem tampouco à 
omissão de ação, porque, na época, o pai era o único sustentáculo e arrimo possível. Com a morte da tia-avó e do pai, a deliberação moral assume novos contornos, porque abre outros cursos de solução cujas condições de realização dependem de planejamento estratégico. Nesses casos, as deliberações interpelam os limites da própria clínica e da moral, convocando a equipe a um olhar ampliado, que requer não só uma leitura atenta da rede-território, mas a compreensão das necessidades em saúde na ótica da esfera pública, isto é, no âmbito dos direitos humanos e de cidadania. Esse pressuposto implica conceber a saúde como direito que vai muito além do acesso aos serviços (esfera individual), para pensá-la em seu espectro mais amplo, de satisfação das necessidades humanas básicas, como: o trabalho, a moradia, a educação, o saneamento, o ambiente, o transporte etc. Isso só é possível com planejamento.

A necessidade de uma visão ampliada como valor aponta para a definição de ações do momento operativo. No caso de Judite, os tradicionais encaminhamentos às redes não seriam resolutivos, pois os vínculos socioinstitucionais não estavam construídos. A equipe precisava ser a referência e vínculo para essa família que enfrentava tantas perdas e dificuldades. Por isso, o planejamento foi uma ferramenta potente para guiar a ação da equipe para além do espaço circunscrito da rede de saúde local.

Integrando a microrrede da região, a equipe pôde articular uma gama de possibilidades/ dispositivos socioterapêuticos para a família. Em um primeiro momento, analisou-se a precariedade do atendimento prestado pelo CAPS da região, que estava com a equipe incompleta, inviabilizando a oferta adequada de serviços. As condições de saúde de Judite, vontade e impulsos preservados, permitiam que ela pudesse ser incluída em atividades terapêuticas laborais, e essa abordagem estava suspensa há um ano no CAPS. Representantes da equipe de saúde da família e agentes sanitários trouxeram dados atuais sobre o número de pessoas com sofrimento psíquico na região, descobertas pelo atendimento em saúde mental, o que gerou uma reivindicação encaminhada à Conferência Municipal de Saúde, que ocorria naquele semestre, e à Secretaria de Saúde do Município. Nucleouse uma comissão de representantes da microrrede (ONGs e serviços públicos) para monitorar os "itinerários" dessa demanda legítima e necessária à população.

O plano terapêutico de Judite incluiu, ainda, a supervisão coletiva do agente de saúde com a equipe do CAPS, no sentido do apoio à adesão ao tratamento e à família. Quanto ao núcleo familiar, a deliberação da microrrede foi a de fortalecer o papel da irmã de Judite, como cuidadora responsável, mas, também, a de resgatar a importância da presença da mãe, no cuidado da família como um todo. Apesar de a deficiência auditiva dela ser severa, a família desenvolveu uma linguagem básica de sinais que permitia uma comunicação fluente entre si. A questão identificada como "situação-objetivo" era o empoderamento de dona Vera para retomar os cuidados com as rotinas domésticas, das quais havia sido afastada por muito tempo, pela iniciativa do marido. Com o passar do tempo e pela forma como a família lidou com suas dificuldades, ela foi se tornando um membro passivo e sem interferência na vida familiar. Avaliando esse histórico, a equipe entendeu que os impeditivos físicos da mãe de Judite, a deficência auditiva e uma hérnia de disco lombar, poderiam receber uma atenção especializada. Consultas com especialistas foram marcadas com o Centro de Referência da cidade.

Uma diretora de escola do bairro, participante da microrrede, próxima da residência de dona Vera, abriu a possibilidade de sua participação no grupo de idosos que ocorria semanalmente, especialmente nas oficinas com acompanhamento do educador físico da escola, que tinha conhecimento da linguagem de libras. A assistente social do CRAS ficou de verificar a elegibilidade do caso para o recebimento do Benefício Previdenciário (BPC), o que proporcionaria, à família, uma melhoria de sua situação socioeconômica e, à mãe, uma função de coprovedora do lar.

Uma vez definidas as ações planejadas, é necessário apontar responsabilidades que possibilitam o momento avaliativo. Para Marta, irmã de Judite, foi proposta a supervisão dos cuidados de saúde da família, com a precaução de não sobrecarregá-la com a responsabilização por todas as providências e encaminhamentos necessários. Marta estava trabalhando em uma escola municipal, e seu salário era o único meio de sustento da família. A equipe pactuou com Marta a corresponsabilização clínica, proporcionando a criação de um vínculo de confiança indispensável à resolutividade do caso. Além disso, Marta foi estimulada a desenvolver, com a irmã e com a mãe, atitudes educativas de apoio e autonomia, num processo de aprendizagem mútua de superação e resiliência. 
Marta, após três meses de contatos regulares com a Unidade de Saúde, mais confiante em relação aos propósitos da equipe e da rede, e com os resultados que já sinalizavam melhoras, se dispõe a participar das reuniões quinzenais da comissão local de saúde e, com isso, passa a ser uma usuária militante de seu território. Ela começa a perceber a dimensão coletiva da saúde e, com ela, que as necessidades abarcam dimensões culturais, epidemiológicas, históricas do território, e, ao mesmo tempo, os "carecimentos" individuais da ordem do adoecimento, do sofrimento e da cura.

Nesse processo, traz para a sua escola o debate sobre educação em saúde, saúde e ambiente, e organiza, no final do ano, junto com a microrrede, a primeira Olimpíada da Promoção da Saúde. Motivada pela equipe de referência, ela traz sua família para colaborar na organização, fortalecendo, ainda mais, os vínculos comunitários. Um dos temas tratados foi à inclusão na escola, onde especialistas e educandos com deficiências puderam expor seus trabalhos e conquistas. Judite organiza a vinda dos usuários do CAPS a uma das palestras e, também, a exposição dos trabalhos com couro (bolsas, chaveiros, marcadores de livros) produzidos pelo seu grupo.

Os movimentos construídos em um processo de planejamento participativo trouxeram à família a possibilidade de conviver novamente no bairro, não apenas em círculos viciosos de institucionalização, mas em um processo de ocupação do território como espaço social, como contexto dos processos de vulneração e de resiliência. Nesses espaços e relações, se construíram processos coletivos de produção de saúde e de vida.

Com essa reflexão, chama a atenção que, apesar de os "problemas-meio" escaparem à capacidade resolutiva individual da rede local, a gestão da produção da saúde no território requer que sejam reconhecidos e tomados como uma responsabilidade sanitária, no sentido de politizá-los e trazê-los ao coletivo, à trama de relações sociais capaz de direcionar sua resolução.

Esse foi o caso do CAPS da rede que foi devidamente reestruturado, podendo atender os usuários de forma integral. Nessa experiência, ainda pode ser destacado que, pelo protagonismo dos sujeitos coletivos instituídos, a Vigilância em Saúde da região passou a ter uma presença efetiva nas reuniões de microrrede e em todas as escolas municipais e estaduais do território, tornando-se fonte de elementos e informações para a deliberação e o planejamento rumo ao curso ótimo para solução do caso. O convite de Marta para que as equipes integrassem a Semana de Promoção da saúde em sua escola abriu muitas outras portas à Vigilância, para além do puro registro de eventos de morbidade, porque possibilitou outros acessos ao território. Trabalhar com a comunidade escolar ampliou o raio de ação das equipes, que passaram a ter agendas e demandas no âmbito da educação em saúde. A Atenção Básica e a Vigilância, conduzidas pelo "caso Judite", com os recursos da deliberação e planejamento estratégico, descobriram outras formas e itinerários de produzir saúde, junto ao território vivo onde as necessidades brotam e demandam atenção e cuidado.

Saúde e doença são fatos objetiváveis cientificamente, mas as ideias sobre saúde e doença são construções, individuais e coletivas, que variam segundo o modo de entender e gerir fatos, valores e deveres, implicados no caso concreto ${ }^{20}$. O processo saúde-doença, portanto, trata de fatos e valores/ fins ao mesmo tempo, que confluem na operacionalização da produção de saúde. É disso que a atenção básica deveria dar conta no território, tendo, as equipes, de lançarem mão de recursos da clínica e da vigilância, do planejamento e da gestão, que permitam plasmar as diferentes dimensões da realidade que possibilitam a decisão e a operação dos cursos de ação.

\section{Considerações finais}

Essa experiência tornou-se um ícone para a equipe e para a microrrede, pois os processos de trabalho foram se orientando pela aprendizagem do planejamento coletivo realizado em torno das necessidades de uma família, como uma exigência ética da própria deliberação clínica. Apostar no potencial de uma família extremamente vulnerada social e clinicamente, exigiu planejamento estratégico por parte da equipe e da rede e disponibilidade de "querer fazer", engajando e implicando técnicos, agentes e demais membros da rede para trilharem caminhos virtuosos de sabedoria prática, que foram se abrindo na processualidade do cuidado deliberado e planejado com corresponsabilidade. 
Diante dessa experiência, pode-se defender a tese de que a efetividade da deliberação moral da clínica, no âmbito da atenção básica, precisa incorporar, em seus cursos de ação, os processos de planejamento estratégico em interação com a macrogestão e com a vigilância em saúde.

\section{Colaboradores}

José Roque Junges responsabilizou-se pelo tema, argumentos, discussão e escrita do artigo. Rosangela Barbiani responsabilizou-se pela discussão, elaboração do caso concreto e melhoria da redação do texto. Elma Lourdes Campos Pavone Zoboli fez a revisão final e aperfeiçoou os argumentos e a redação do manuscrito.

\section{Referências}

1. Ayres JRCM. Cuidado e humanização das práticas de saúde. In: Deslandes SF, organizadora. Humanização dos cuidados em saúde: conceitos, dilemas e práticas. Rio de Janeiro: Fiocruz; 2006. p. 49-83.

2. Ministério da Saúde. Política Nacional de Humanização. A Humanização como eixo norteador das práticas de atenção e gestão em todas as instâncias do SUS. Brasília (DF): MS; 2004.

3. Gracia D. La deliberación moral: el método de la ética clínica. Med Clin (Barc). 2001; $117(1): 18-23$

4. Gracia D. Moral deliberation: the role of methodologies in clinical ethics. Med Health Care Philos. 2001; 4(2):223-32.

5. Cortina A. Ética aplicada y democracia radical. Madrid: Tecnos; 1997.

6. Lefèvre $F$, Lefèvre AMC. O discurso do sujeito coletivo: um novo enfoque em pesquisa qualitativa (desdobramentos). Caxias do Sul: Educs; 2005.

7. Campos RO. O planejamento no labirinto: uma viagem hermenêutica. São Paulo: Hucitec; 2003.

8. Weber M. A política como vocação. Brasília (DF): UnB; 2003.

9. Junges JR, Schaefer R, Prudente J, Mello REF, Silocchi C, Souza M, et al. A visão moral dos profissionais de uma Unidade Básica de Saúde e a Humanização. Interface (Botucatu). 2011; 15(38):755-62.

10. Morin E. O Método 6; ética. Porto Alegre: Sulina; 2005.

11. Zoboli ELCP. Bioética clínica na diversidade: a contribuição da proposta deliberativa de Diego Gracia. In: Pessini L, Barchifontaine CP, Hossne W, Anjos MF, organizadores. Ética e Bioética clínica no pluralismo e diversidade: teorias, experiências e perspectivas. Aparecida: Ideias \& Letras; 2012. p. 149-63. 
12. Teixeira C, Sá MC. Planejamento \& gestão em saúde: situação atual e perspectivas para a pesquisa, o ensino e a cooperação técnica na área. Cienc Saude Colet. 1996; 1(1):82-103.

13. Schraiber LB, Peduzzi M, Sala A, Nemes MIB, Castanhera ERL, Kon R. Planejamento, gestão e avaliação em saúde: identificando problemas. Cienc Saude Colet. 1999; 4(2):221-42.

14. Paim J. Planejamento em saúde para não especialistas. In: Campos GWS, Minayo MCS, Akerman M, Drumond Júnior M, Carvalho YM, organizadores. Tratado de Saúde Coletiva. São Paulo: Hucitec; 2006. p. 767-82.

15. Rivera FJU, Artmann E. Planejamento e gestão em saúde: histórico e tendências com base numa visão comunicativa. Cienc Saude Colet. 2010; 15(5):2265-74.

16. Rivera FJU, Artmann E. Planejamento e gestão em saúde: conceitos, história e propostas. Rio de Janeiro: Fiocruz; 2012.

17. Rivera FJU, Artmann E. Planejamento e gestão em saúde: flexibilidade metodológica e agir comunicativo. Cienc Saude Colet. 1999; 4(2):355-65.

18. Matus C. Política, planejamento e governo. Brasília (DF): Ipea; 1993.

19. Gracia D. Fundamentaciones de bioética. In: Como arqueros al blanco: estudios de bioética. Madrid: Triacastela; 2004. p. 105-28.

20. Gracia D. Construyendo la salud. In: Construyendo valores. Madrid: Triacastela; 2013. p. 203-10.

Junges JR, Barbiani R, Zoboli ELCP. La Planificación Estratégica como exigencia ética para el equipo y la gestión local de la Atención Básica en Salud. Interface (Botucatu). 2015; 19(53):265-74.

Las premisas de que no se puede cuidar de los individuos sin atender a sus colectivos y de que atención y gestión son inseparables muestran que la deliberación moral de la clínica en el cuidado individual no puede separarse de la planificación estratégica del equipo y de la gestión local. Esta planificación precisa estar integrada con la vigilancia para detectar necesidades en salud del contexto de atención, articulada con la gestión central del municipio para pactar acciones intersectoriales necesarias para el cuidado de la salud ampliado de los individuos y de la población. Las decisiones morales de deliberación clínica exigen, para hacerse concretas, condiciones y medios dependientes de la planificación estratégica en el territorio. Al consultar el proceso de deliberación moral propuesto por Gracia y de planificación estratégica propuesto por Matus se descubre una gran homología entre sus etapas: cognitivo, valorativo, operativo, evaluativo. El artículo concluye con un caso concreto complejo de atención básica en donde están implicadas esas etapas.

Palabras clave: Atención Básica de la Salud. Etica. Gestión. Vigilancia. Planificación Estratégica.

Recebido em 01/05/14. Aprovado em 09/09/14. 